\title{
Fly pollination of dichogamous Angelica sylvestris (Apiaceae): how (functionally) specialized can a (morphologically) generalized plant be?
}

\author{
Radosław Niemirski $\cdot$ Marcin Zych
}

Received: 26 February 2010/ Accepted: 2 April 2011/Published online: 12 May 2011

(C) The Author(s) 2011. This article is published with open access at Springerlink.com

\begin{abstract}
Because of the flower morphology and high number of insect visitors, plants of the family Apiaceae are regarded as generalists in terms of pollination systems. Recent studies however showed some degree of, at least, ecological specialization in some members of this taxonomical group and indicated interesting patterns of insect visitor behavior: discrimination between umbel sexual phases. To test whether this is true in case of other members of the family, over two years we studied the pollination biology of a common European umbellifer, Angelica sylvestris, a species considered by some authors as a supergeneralist. Although its flowers were visited by over 70 species of insects grouped in 10 morphospecies, only a relatively narrow assemblage of muscoid and syrphid flies, rather constant in both study years, contributed to pollination. These insects did not exhibit any preferences toward plant sexual phases. Based on our results and available literature, we discuss the concept of specialization/generalization of the A. sylvestris pollination system, especially in the context of the "unspecialized" floral morphology characteristic for members of the Carrot family.
\end{abstract}

Keywords Dichogamy - Diptera - Generalization · Pollinator importance $\cdot$ Specialization · Umbelliferae . Umbels

R. Niemirski · M. Zych ( $\bowtie)$

University of Warsaw Botanic Garden,

Al. Ujazdowskie 4, 00-478 Warsaw, Poland

e-mail: mzych@biol.uw.edu.pl

\section{Introduction}

Flowers of the umbellifers (species of the Carrot family) are easily recognized by their flat, umbrella-like, usually white inflorescences (compound umbels) visited by numerous insect taxa from several taxonomic orders, usually providing the animals with pollen and nectar throughout the whole flowering period (Ellis and Ellis-Adam 1993, 1994; Zych 2004; Zych et al. 2007). According to Corbet (2006), they are allophilous plants (i.e., species with "flowers with fully exposed nectar and little or no intrafloral temperature elevation") that attract allotropous (small body mass and little or no endothermy) and hemitropous insects (larger body mass with some endothermy), which is an approximate equivalent of phenotypically generalized plants as described in Ollerton et al. (2007). The umbelliferous plants are often associated with generalist pollination systems (Proctor et al. 1996), and when a number of visitor taxa are concerned, at least a few of them, including Angelica sylvestris, were included in the "top 10" list of plant generalists (Olesen et al. 2007). This opinion is however mostly based on lists of flower visitors, and detailed analyses of pollinator performance on umbels of various Apiaceae plants show some degree of, at least, ecological specialization (e.g., Bell and Lindsey 1978; Lindsey 1984; Zych 2007).

The plants of the family Apiaceae are mostly visited by flies (Drabble and Drabble 1927; Proctor et al. 1996), but detailed studies showed that, apart from dipteran pollinators (Zych 2007), their flowers may also be pollinated by beetles (Lamborn and Ollerton 2000), bees or other hymenopterans (Bell and Lindsey 1978; Lindsey 1984; Davila and Wardle 2002, 2008), including ants (Carvalheiro et al. 2008).

Most of umbellifers are dichogamous; however, the overlap of sexual phases may be substantial in some taxa, 
whereas their separation may be complete in others (Bell 1971; Schlessman et al. 2004), which in the case of an absolute dichogamy leads to the presence of temporally unisexual flowers. As recently demonstrated for various umbelliferous plants from three continents (Australia: Davila and Wardle 2007, Europe: Zych 2007, and N America: Schlessman et al. 2004), such "temporal dioecism" (sensu Cruden and Hermann-Parker 1977) may influence the behavior of pollinators (and/or flower visitors) that discriminate between the flower sexual phases, avoiding, for instance, the pistillate phase when pollen grains are missing. This in turn greatly influences the performance of particular insect taxa in providing pollination services to plants, as some insects in search for pollen visit solely male phase flowers and do not contribute to pollination (Zych 2007).

In spite of their general morphological (including floral) uniformity, some umbellifers are suggested to harbor many subtle but effective floral adaptations connected to pollination (Bell 1971). Indeed several members of the family were proved to exhibit cryptic flower specialization that results in oligolectic relationships with bee pollinators (Lindsey 1984; Lindsey and Bell 1985). Although all the above makes them an excellent subject for studies on pollination systems and their evolution, recently only a few authors have provided a detailed examination of the pollination biology of particular taxa. To fill this gap in our understanding of these aspects of the biology of this plant group and to test the Ellis and Ellis-Adam (1993, 1994) predictions on only superficial uniformity of their pollination biology, we decided to study the pollination system of a widely distributed European protandrous umbellifer, Angelica sylvestris L., a plant indicated by these authors as being visited by 245 insect species (Ellis and Ellis-Adam 1993). In particular we were interested whether: (1) all groups of insect visitors contribute equally to pollination, and if not, what are the main pollinators; (2) the pollinators' assemblage is subject to year-to-year variation; (3) any of the insect groups show preferences towards floral sexual phases that may restrict their quality as pollinators; and (4) how specialized/generalized is the plant's pollination system?

\section{Materials and methods}

\section{Study species}

Angelica sylvestris is a member of the family Apiaceae (= Umbelliferae), subfamily Apioideae, recently classified in the tribe Selineae (Spalik et al. 2004). It is a perennial, producing cauline leaves arranged in a rosette and erect flower stems up to over $2 \mathrm{~m}$ tall (Cannon 1968). Flowers are open and arranged in large multirayed inflorescences (compound umbels), and visited by 245 insect species, mostly dipterans (Ellis and Ellis-Adam 1993; a detailed list of insect visitors in our study site is given by Zych et al. 2007), searching for pollen and nectar exuded by exposed swollen base of the style (stylopodium). Petals are greenish white to pinkish, flower symmetry is mostly actinomorphic, but the outer flowers in umbellets may be slightly zygomorphic. The flowers are dichogamous and are reported to be protandrous (Knuth 1898), although we found no detailed information on the level of protandry in the literature.

The plants are andromonoecious, i.e., produce hermaphroditic (perfect) flowers along with functionally male ones (generally a rule in Apiaceae, Schlessman et al. 2004), and the percentage of the former is quite variable within umbels of various orders: the main (primary) inflorescence usually consists of $100 \%$ hermaphrodite flowers, while the latest developing umbels may be $100 \%$ male. The plant reproduces by seeds; during our study we found no signs of vegetative reproduction (M. Zych, R. Niemirski, personal observation).

Angelica sylvestris is usually found in wetlands, damp and shady places, and is distributed almost throughout all Europe (Cannon 1968). It is a natural component of many plant communities in Europe, and in Poland is regarded as characteristic for meso- or eutrophic traditionally and extensively used damp meadows.

\section{Study site}

The observations were conducted in 2006 and 2007 in a large population of A. sylvestris (several thousand plants growing in an area of approximately $5 \mathrm{ha}$ ), in the damp meadow complex on the small Ruż river, in the vicinity of the village Kleczkowo (N 5302.9' E 21 ${ }^{\circ} 51.8^{\prime}$, NE Poland, Ostrołęka district, Mazowieckie Voievodeship). The investigated community is rich in many endangered Polish Red Book plant species (e.g., Betula humilis, Dianthus superbus and Polemonium caeruleum, Zych and WerblanJakubiec 2004, 2005). The plants grew in an extensively used hay meadow on peat soils.

Flowering phenology

To determine the length of the flowering period and the level of dichogamy, in the 2006 season, we randomly marked 50 individual plants with primary umbels in the pre-flowering stage and, starting from the day when the first bud burst open, approximately every $12 \mathrm{~h}$ (in the morning and evening) we noted all the sexual phases present in the first and subsequently developing umbels until the last order umbels ceased to flower. Flowering time 
of an individual flower was divided into six periods: (1) bud; (2) bud open, beginning of the male phase, anthers closed; (3) anthesis; (4) neuter phase, stamens wilt, elongation of the styles; (5) female phase, stigmas spread apart and receptive, petals start to fall off; (6) post-pollination phase, fruit develops. Two-way ANOVA was performed on the length of a flowering period, with umbel order and umbel sexual phase as factors, followed by post-hoc Fisher's LSD tests (due to a small sample size and/or unisexual umbels we excluded data for tertiary and quaternary inflorescences). For each of the selected plants we also measured the height of the main steam, number of rays in a primary umbel and the number of lateral umbels.

Flower visitors and insect identification

We conducted main field observations in 27-31 July 2006 and 1-4 August 2007, a peak flowering time for A. sylvestris in NE Poland. The method used was already applied during studies on pollination of Heracleum sphondylium (Zych 2002, 2007). Only primary umbels in either the male or the female phase were chosen for observations, because in most umbellifers these umbels are mainly responsible for seed production. Observations started at $0800 \mathrm{~h}$ (the first recording) and ended at $1930 \mathrm{~h}$ (the last capturing). We conducted some pre-study observations that showed that before $0800 \mathrm{~h}$ and after $1900 \mathrm{~h}$ flowers of A. sylvestris are visited by insects very scarcely; especially no typically nocturnal insects (e.g., sphingid moths) were recorded. Extended but unquantified observations conducted daily from 1 August until 5 September in 2006 and approximately every 2 weeks during the population flowering period in 2007 showed that at each point the floral entomofauna in highly fly-dominated, and no additional insect groups appear earlier or later in the season.

During each study day we would normally conduct 12 rounds of observations; however, in case of strong winds or rain, the observations were suspended, and the remaining rounds were completed at the corresponding hour on subsequent days. Each round lasted $1 \mathrm{~h}$ and consisted of three phases: random choice of an umbel, video recording (10 min, using the NV-GS75 digital camera, Panasonic, Matsushita Electric Industrial Co., Ltd.) and insect sampling (10 min). Once selected, umbels were not excluded from the subsequent round, and therefore it was possible that the same umbel was observed more than once. In each year we performed 24 rounds of observations (i.e., the equivalent of two full observation days) for each of the two umbel sexual phases, altogether summing up to $960 \mathrm{~min}$ of video records and $960 \mathrm{~min}$ of insect capturing over 2 study years.

Visit frequency of Muscoid flies and non-dipterans was analyzed using two-way ANOVA with study year and umbel sexual phase as factors followed by post-hoc Fisher's LSD tests; data for Hairy syrphids and Non-hairy syrphids were highly non-normal and could not be successfully transformed, so we performed independent Kruskal-Wallis ANOVAs respectively with study year or sexual phase as a factor.

For analyses of diurnal insect activity we performed one-way ANOVA on visit frequency of Muscoid flies on pooled data from both sexual phases in 2006 and 2007, with part of day as a factor, and Kruskal-Wallis ANOVA for the remaining insect groups. All statistical calculations were performed using STATISTICA 7.1 (Stat Soft Inc. 2005).

During insect sampling all individuals visiting the selected umbel were collected and anaesthetized with ethyl acetate, pinned and stored for further investigation of their pollen loads. We excluded from the analyses aphids and other small, sap-sucking insects (e.g., Thysanoptera), together with insects smaller than $1 \mathrm{~mm}$, as these animals were usually observed clinging to the stylopodium and, even when moving around the flower, are too small to effectively touch the stigma or anthers.

We based insect identification on the identified insect collection from the same site (Zych et al. 2007). In doubtful cases insects were identified by one of the authors (MZ) or specialists-entomologists.

\section{Pollen load analyses}

For the investigation of insect pollen loads we used the method described in Zych (2002, 2007). An individual insect was put on the microscopic slide, and using a thin brush we removed pollen from its body until no remaining pollen was visible. This was done under a stereoscopic microscope. The pollen was then stained with a drop of acetoorceine and covered with microscopic cover glass. The brush was carefully cleaned after each insect to prevent contamination of the next sample. We analyzed samples using a light microscope. In small loads (ca. 300 pollen grains), we counted all A. sylvestris pollen grains, and in case of a large sample we counted pollen grains from nine, evenly distributed fields of view. Arithmetic mean of the counts, after extrapolation, was used to calculate the pollen load in a given sample. In the case of bees we removed their hind legs prior to the above procedure so that corbicular pollen loads could not contaminate the sample.

Pollen grains of $A$. sylvestris resemble those of other Apiaceae; therefore, during the examination of pollen loads there is a possibility of misidentification if other umbellifers grow in the same site. In our study site, close to the studied populations plants, no other flowering Apiaceae species were encountered-the closest flowering 
representatives of the family, individuals of Daucus carota, grew approximately $1 \mathrm{~km}$ away from the studied plants. We compared the pollen grain size of the two taxa (measured were 100 pollen grains from five randomly sampled anthers from each of the species) and found that $A$. sylvestris produces significantly smaller pollen grains $(26.2 \pm$ $2.66 \times 12.8 \pm 1.29 \mu \mathrm{m})$ than $D$. carota $(28.7 \pm 2.2 \times$ $14.0 \pm 1.1 \mu \mathrm{m}) \quad$ (comparisons for both dimensions $p<0.005$, Student's $t$ test); however, in spite of size difference their overall similarity makes it difficult to distinguish under low magnifications in the light microscope. To see if the insects carry mixed pollen loads, we randomly browsed several microscopic slides with the pollen loads and found only minute quantities of pollen (one to few pollen grains) that could be attributed to D. carota. Therefore, we eventually treated all the Apiaceae-type pollen grains as those belonging to A. sylvestris as we concluded that although it is possible for various insects to fly this far, we assume it to be rather unlikely because the carrot plants grew in completely different habitats: dry, sandy road and railway verges isolated by several rows of trees from our study site, a typical wetland habitat.

\section{Pollinator performance}

Although direct methods measuring pollinator efficiency, e.g., measuring pollen loads deposited on a stigma by a given pollinator species, or seed set after visits by certain pollen-carrying vectors or after exclusion of a given insect visitor, are the best descriptors of pollinator importance (Pellmyr 2002), it is practically impossible to use them in plants such as Apiaceae, with hundreds of very small flowers packed into large inflorescences, visited at the same time by several dozens (which daily adds to thousands) of insects from diverse taxonomic groups. For similar taxa indirect methods must be used to give an overview of the plant's pollination system. However approximate, they must not relay only on number or frequency of visits but also include other measures of animal performance on flowers, for instance insect relative abundance, its pollen load and behavior on a flower (inflorescence). The combination of the above elements, even though it is far from an ideal description of an insect efficiency, seems at least a reasonable indication of pollinator quality (Lindsey 1984; Lamborn and Ollerton 2000; Zych 2002, 2007).

For estimating the pollination quality of insect visitors recorded on flowers of $A$. sylvestris, we therefore decided to use an indirect method (pollinator importance measure, I) based on counts of the insects' pollen loads, and observations of insect frequency, abundance and behavior on the flowers that proved to be helpful in estimation of effective pollinators of other umbellifers (Zych 2002, 2007):
$\mathrm{I}_{\mathrm{x}}=\mathrm{V} \times \mathrm{U} \times \mathrm{PL}$,

where: $I_{\mathrm{X}}$ is importance of insect species $\mathrm{X}, V$ is the abundance (number of recorded visits of species $\mathrm{X}+$ number of captured individuals of species $\mathrm{X}) /($ total number of recorded visits + total number of captured individuals), $U$ is the umbel penetration ratio (mean number of umbellets visited by species $\mathrm{X}$ within an umbel/ mean number of umbellets in an average umbel in the population surveyed); PL is the average pollen load (number of pollen grains) carried by an individual of species X. I was calculated for every season and floral sexual phase (therefore $I_{\mathrm{f}}$ stands for pollinator importance during the female phase of umbels and $I_{\mathrm{m}}$ for pollinator importance during the male phase of umbels), and then summed for all the insect groups for each study year and sexual phase of the flowers to obtain the maximum possible value. The importance coefficient, indicating the insect importance level on male $\left(\mathrm{IC}_{\mathrm{m}}\right)$ or female $\left(\mathrm{IC}_{\mathrm{f}}\right)$ umbels of each insect taxon/group, was expressed as a percentage of the sum value. We followed the assumptions of Zych (2007) that for 'good' (true) pollinators $\left(I_{\mathrm{f}(\text { female }) /} I_{\mathrm{m} \text { (male) }}\right)$ scores should be greater than 0 , but at the same time the key pollinators should also have $\mathrm{IC}_{\mathrm{f}}$ at least greater than $1 \%$.

\section{Results}

Flowering period and protandry

Most of the studied plants $(98 \%)$ produced at least two orders of inflorescences; tertiary umbels were present on almost half of the plants (on average 3-4 secondary and tertiary umbels per plant), and only two of them $(4 \%)$ produced quaternary inflorescences. Only primary and secondary umbels consisted of both perfect and staminate flowers, while tertiary and quaternary umbels were totally male. The average height of the main inflorescence was $0.83 \mathrm{~m}( \pm 0.149)$, and the whole flowering period for an average individual lasted approximately 21 days. The umbels, depending on the order, lasted approximately 4-7 days. In hermaphrodite inflorescences (i.e., primary and secondary), the male phase was always significantly longer than the female phase (2-3 times, $p<0.01$, posthoc Fisher's LSD test).

The plants exhibited strong protandry on the level of an individual flower, umbel and whole plant. Short overlap in sexual phases within primary and/or secondary inflorescences was observed in approximately $60 \%$ of plants and lasted on average $1.5 \mathrm{~h}$ in primary umbels (overlap in $50 \%$ of plants) and $7 \mathrm{~h}$ in secondary umbels (overlap in $20 \%$ of plants). No overlap among the subsequently blooming umbels was observed. 
Fig. 1 Total number of visits of insects from various functional groups to umbels of Angelica sylvestris during observations conducted in the years 2006-2007; each category represents summed data from capturing and video recordings over 24 censuses $(240 \mathrm{~min}$ ) for a given sexual phase and year. Because of the small sample size Bees, Wasps and Ichneumonids were included into a larger category of Hymenoptera and Hairy syrphids, and Non-hairy syrphids were included into a larger category of Syrphids; $\mathrm{M}$ male phase umbels, $\mathrm{F}$ female phase umbels

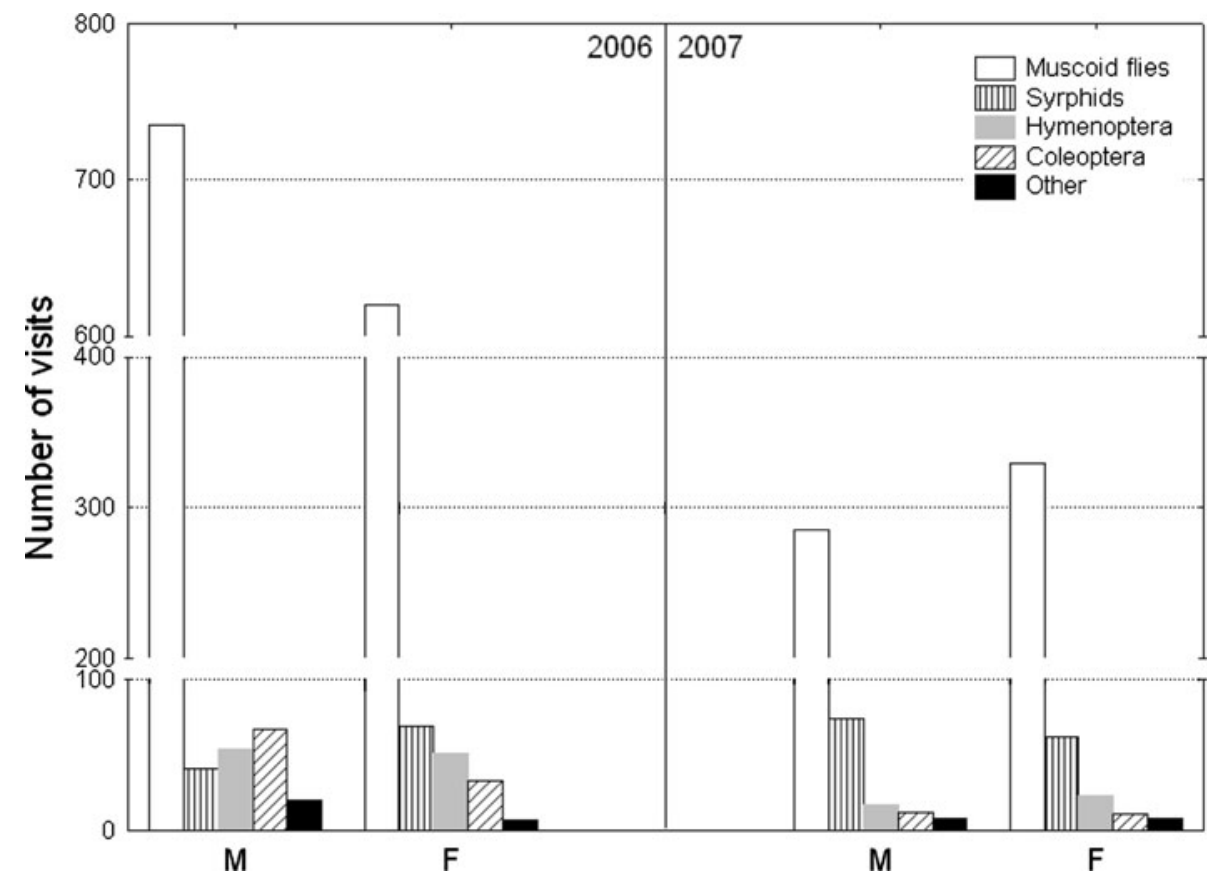

Flower visitors

During both seasons we video recorded and captured 2,527 insects from over 72 taxa representing seven taxonomic orders: Diptera, Coleoptera, Heteroptera, Hymenoptera, Lepidoptera, Neuroptera and Orthoptera (a detailed list of insect visitors is given in Zych et al. 2007). Dipterans were the most constant and abundant group of visitors on umbels in both study seasons and sexual phases. Most of recorded dipterans resembled the 'Muscoid type' (i.e., members of families Muscidae, Tachinidae, Sarcophagidae and Anthomyidae) and 'Hoverfly type' insects (i.e., members of family Syrphidae), and were hardly identifiable and distinguishable on video recordings, which greatly impeded our analyses. Therefore, basing on general morphological similarities, we decided to divide them into ten morphospecies: Medium muscids, Large muscids, Hairy syrphids, Non-hairy syrphids, Lucilia, Bees, Wasps, Beetles, Ichneumonids and Other (Appendix 1, Table 4), which is a common solution in similar studies (e.g., Davila and Wardle 2008). Three of our morphospecies (Medium muscids, Large muscids, Lucilia), although clearly identifiable, could be further included into one functional groups (sensu Fenster et al. 2004) of Muscoid flies, based on their general characters such as relative size, hairiness and behavior, whereas in case of the other morphospecies, they were later treated as equivalent to functional groups bearing the same name.

In 2006 Muscoid flies conducted over $75 \%$ of visits on male phase umbels and almost $80 \%$ on female phase umbels (summed data from video records and captures over 24 censuses), in 2007 over $72 \%$ on male and $76 \%$ on female sexual phase. In case of hoverflies (summed data for Hairy syrphids and Non-hairy syrphids), the numbers were rather similar for both study years, but their relative share increased from $4.5 \%$ in male and $8.8 \%$ in female phase umbels in 2006 to 18.7 and $14.3 \%$, respectively, in 2007 . The results for Coleopterans (2006: $7 \%$ on male and $4 \%$ on female phase umbels, 2007: 3 and 2\% respectively) and Hymenopterans (2006: approximately 6\% on both sexual phases, 2007: 4\% on male and $5 \%$ on female phase umbels) were similarly low. The remaining 2-3\% of visits in each study year were made by insects from other taxonomic groups (Fig. 1).

As shown above, dipterans were the most abundant flower visitors; therefore, for most of the analyses we only show the results for the morphospecies representing this group and the summed data for the remaining insects. Mean visit frequency of Muscoid flies to umbels was similar for both umbel sexual phases in the same year, but differed across years (Fig. 2). In 2006 on average we observed 22.3 visits per census $(10 \mathrm{~min})$ to male phase umbels and 20.6 visits/census to female phase umbels. In 2007, when the summer was cold and rainy, the numbers dropped significantly to 9.5 visits/census to male phase umbels and 10.7 visits/census to female phase umbels (for Total Insects 13.4 and 14.5 visits/census, respectively). For Hairy syrphids, Non-hairy syrphids and the remaining morphospecies, the mean number of visits usually did not exceed 2 , except in 2006 for the remaining morphospecies when it was 4.8 and 3.0, respectively, for male and female phase umbels (Fig. 2). The results of two-way ANOVA for Muscoid flies and non-dipterans show that the umbel sexual phase had no effect on their visit frequency, whereas the effect of a study 

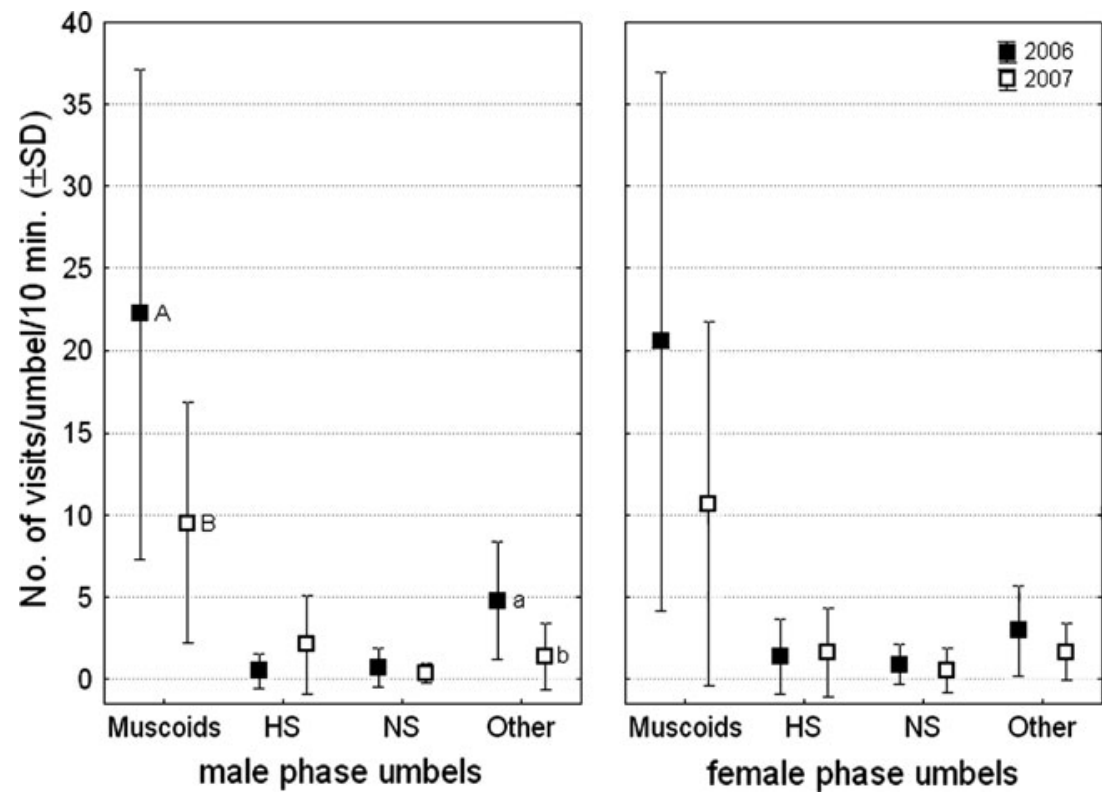

Fig. 2 Mean visit frequency (and SD) of insects from various functional groups to male and female umbel phases of Angelica sylvestris over 2 study years (2006, solid squares; 2007, empty squares); Muscoids, Muscoid flies; HS, Hairy syrphids; NS, Nonhairy syrphids; Other, all remaining morphospecies (for details, see Insect visitors paragraph in Results). Each point in the graph

year was clear (Table 1); the differences however were only statistically significant for male phase umbels, while for female phase umbels, although quite large especially for Muscoid flies, they were statistically insignificant (Fig. 2). These two factors (study year and umbel sexual phase) did not effect visit frequency of Hairy syrphids, Non-hairy syrphids and the remaining morphospecies.

In the case of Muscoid flies we recorded significant differences (one-way ANOVA, $F_{4,92}=40,41378$, $p<0.001)$ in the diurnal visitation pattern with peak visit frequency at noon (1100-1300) and drop in the frequency of visits in the evening (Fig. 3). The remaining morphospecies exhibited a similar pattern of diurnal activity, except for wasps, where their peak activity was recorded in the morning, dropping to the lowest numbers in the evening; these differences however were statistically insignificant.

Insect pollen loads

Not all the insect visitors to flowers of Angelica sylvestris carried its pollen grains on their bodies. This group usually consisted of approximately $30 \%$ of all captured taxa. This proportion however was not true for female umbels in 2006 when $95 \%$ of captured insect taxa carried significant pollen loads.

Pollen-carrying capacity of the studied insects was very variable. The size of pollen loads differed greatly both within and between the insect groups, and also between represents the mean from 24 censuses. Study year was found to significantly affect visit frequency only on male phase umbels for Muscoids and Other (means with different letters are different respectively at $p<0.05$ and $p<0.005$; post-hoc Fisher's LSD test); no effect of either study year or umbel sexual phase was found for HS and NS (Kruskal-Wallis ANOVA)

study years. The largest single pollen load, 1,142 pollen grains, was recorded on an individual of Eurithia consobrina (Tachinidae) attributed to Large muscids that visited a female phase umbel in 2006. Considering morphospecies in 2006, the largest pollen loads were carried by Hairy syrphids (on average 634 pollen grains on male and 519 on female umbels), followed by Large muscids ( 283 and 269 pollen grains, respectively) and Lucilia (148 and 168 pollen grains, respectively). A similar pattern was observed in 2007, although the size of the pollen loads was much smaller (Hairy syrphids: 196 and 92, Large muscids: 113 and 71, Lucilia: 41 and 138 pollen grains on male and female umbels, respectively; Table 2).

\section{Key pollinators}

Although the Pollinator Importance Coefficients (ICs) calculated for ten morphospecies present on umbels of A. sylvestris showed considerable differences both among the morphospecies and between study years, every year the most important insects contributing to pollen export and import were dipterans from the three morhospecies included into the Muscoid flies functional group (Medium muscids, Large muscids, Lucilia). Their summed IC usually reached $80-85 \%$, except male phase umbels in 2007 when it constituted $51.9 \%$ (Fig. 4). Insects from this functional group in both study years showed higher IC values for male phase umbels, but exhibited rather 
Table 1 Results of two-way ANOVA on frequency of visits of Muscoid flies (combined data for Medium muscids, Large muscids and Lucilia) and non-dipteran insects to umbels of Angelica sylvestris

\begin{tabular}{|c|c|c|c|c|c|}
\hline Source & $d f$ & SS & MS & $F$ & $p$ \\
\hline \multicolumn{6}{|l|}{ Muscoid flies } \\
\hline Year & 1 & 3071.34 & 3071.34 & 7.2864 & 0.008 \\
\hline Sex & 1 & 1.76 & 1.76 & 1.7600 & $\mathrm{~ns}$ \\
\hline Year $\times$ sex & 1 & 46.76 & 46.76 & 0.1109 & $\mathrm{~ns}$ \\
\hline Error & 92 & 39201.14 & 421.52 & & \\
\hline Total & 96 & 42321.00 & & & \\
\hline \multicolumn{6}{|l|}{ Non-dipterans } \\
\hline Year & 1 & 133.01 & 133.01 & 9.2684 & 0.003 \\
\hline Sex & 1 & 14.26 & 14.26 & 0.9937 & ns \\
\hline Year $\times$ sex & 1 & 27.09 & 27.09 & 1.8879 & ns \\
\hline Error & 92 & 1334.64 & 14.35 & & \\
\hline Total & 96 & 1509.00 & & & \\
\hline
\end{tabular}

'Year' denotes the effect of study year (2006 vs. 2007), and 'sex' the effect of umbel sexual phase (male vs. female)

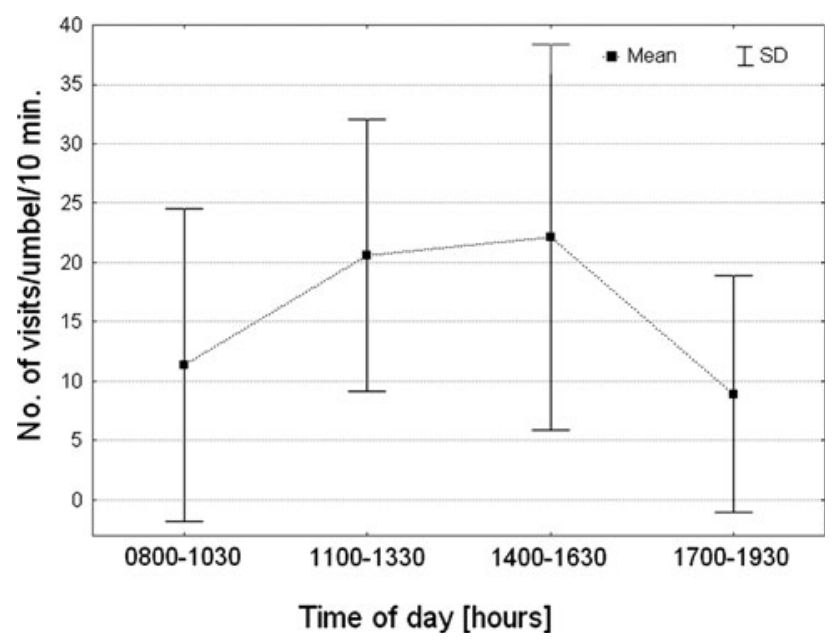

Fig. 3 Visit frequency of Muscoid flies on umbels of Angelica sylvestris during different parts of the day (pooled data for both umbel sexual phases in 2006 and 2007). Hourly recordings were clustered: 0800-1030 (morning), 1100-1330 (noon), 1400-1630 (afternoon) and $1700-1930$ (evening). There is a statistical difference in daily activity of this morphospecies (one-way ANOVA $F_{4,92}=40,41378$, $p<0.001, N=24$ for each point on the graph)

balanced performance on both sexual phases of the umbels. More variable results were shown for Hairy syrphids: in 2006 they performed better on female phase umbels (15.2 vs. $5.4 \%$ ) and in 2007 on male phase umbels (41.9 vs. 14.8\%). Within Diptera the worst performance on umbels was recorded for individuals of Non-hairy syrphids. Although they usually made more visits when compared to Hairy syrphids, the level of their importance coefficient was always similarly low and did not exceed $0.6 \%$. The remaining morphospecies were responsible for a minor contribution to pollen export and import (always less than $10 \%$ irrespectively of sexual phase and study year). In either study year they performed better on male phase umbels. Within this group bees for instance contributed only to pollen export (1.2 and 5.2\%, respectively, in year 2006 and 2007).

When $I_{\mathrm{f}} / I_{\mathrm{m}}$ ratio is concerned $\left(I_{\mathrm{f}} / I_{\mathrm{m}} \approx 1\right.$ indicates balanced pollination service), the results greater than 0 were recorded for all the dipteran morphospecies in either study year, for Coleoptera in 2006 and 'Other' in 2007. However when the following two conditions $\left[\left(I_{\mathrm{f}} / I_{\mathrm{m}}\right)>0\right.$ and $\mathrm{IC}_{\mathrm{f}}>1 \%$ ] were applied jointly, the requirements were only met by Medium muscids, Large muscids, Hairy syrphids and Lucilia in both study years (Table 3).

\section{Discussion}

Our studies showed that Angelica sylvestris, similarly to other Apioideae, is an andromonoecious species with the increasing proportion of male flowers in higher order umbels. It may also be characterized by quite strong synchronous intrafloral and interfloral dichogamy (protandry), which means that the sequence of male and female phases is synchronized on the level of a single flower, the whole inflorescence and the plant. This situation represents the 'temporal dioecism' described by Cruden and HermannParker (1977), because at any given moment during the flowering period the plant presents either pollen or receptive stigmas, with no or very short overlap between staminate and pistillate phases within a single flower, umbel or among the umbels of subsequent orders. This mechanism may relatively easily prevent self- (and geitonogamous) pollination. Such a phenomenon was found in other Apiaceae (Cruden 1988) and described by Schlessman et al. (1990) as "multicyclic protandry." Among European umbellifers a similar system can be found, for instance, in Daucus carota subsp. commutatus (Pérez-Bañón et al. 2007), and Heracleum sphondylium (Zych 2007) or North American and Mexican Eryngium species (Cruden and Hermann-Parker 1977; Molano-Flores 2001). It is suggested that in self-compatible plants such as many Apiaceae (see, e.g., Molano-Flores 2001; Davila and Wardle 2002), it acts as a behavioral mechanism of self-incompatibility (Cruden 1988). In the case of A. sylvestris production of selfed seeds is however not absolutely prevented as at least $50 \%$ of plants in the population show a short, 1.5-h-long bisexual period in primary umbels, and the same is true for $20 \%$ of plants in the case of secondary umbels, where the overlap period is even longer.

Flowers of $A$. sylvestris represent an open dish-shaped blossom type (Faegri and van der Pijl 1966), and in our study site are visited by over 70 insect species from seven taxonomic orders (Zych et al. 2007); however, as observed 
Table 2 Components of $I$ (importance) for ten morphospecies (refer to Appendix 1, Table 4 for their detailed description) observed in umbels of Angelica sylvestris during study periods in 2006 and 2007

\begin{tabular}{|c|c|c|c|c|c|c|c|c|c|c|c|c|c|c|c|c|}
\hline & \multicolumn{8}{|c|}{2006} & \multicolumn{8}{|c|}{2007} \\
\hline & \multicolumn{4}{|l|}{ M } & \multicolumn{4}{|l|}{$\mathrm{F}$} & \multicolumn{4}{|l|}{ M } & \multicolumn{4}{|l|}{$\mathrm{F}$} \\
\hline & V & $U$ & $C$ & PL & V & $U$ & $C$ & PL & V & $U$ & $C$ & PL & $V$ & $U$ & $C$ & PL \\
\hline Medium muscids & 376 & 6.3 & 159 & 69 & 316 & 6.0 & 90 & 81 & 105 & 4.7 & 32 & 25 & 120 & 4.7 & 36 & 18 \\
\hline Large muscids & 82 & 10.5 & 19 & 283 & 32 & 11.7 & 6 & 269 & 51 & 6.4 & 9 & 113 & 32 & 8.8 & 17 & 71 \\
\hline Hairy syrphids & 12 & 3.4 & 7 & 634 & 34 & 4.1 & 8 & 519 & 51 & 4.9 & 13 & 196 & 39 & 7.1 & 4 & 92 \\
\hline Non-hairy syrphids & 17 & 2.4 & 5 & 27 & 21 & 4.9 & 6 & 27 & 9 & 5.0 & 1 & 4 & 13 & 1.7 & 6 & 6 \\
\hline Lucilia & 76 & 7.7 & 23 & 148 & 146 & 5.3 & 30 & 168 & 73 & 4.6 & 15 & 41 & 104 & 6.7 & 21 & 138 \\
\hline Bees & 1 & 14.0 & 2 & 210 & 0 & 0 & 1 & 237 & 0 & 13.0 & 1 & 588 & 3 & 1.5 & 0 & 0 \\
\hline Wasps & 48 & 4.8 & 0 & 0 & 31 & 7.5 & 6 & 32 & 14 & 3.7 & 1 & 6 & 17 & 3.3 & 0 & 0 \\
\hline Beetles & 50 & 6.6 & 17 & 136 & 24 & 4.7 & 9 & 38 & 12 & 4.5 & 0 & 0 & 11 & 3.5 & 0 & 0 \\
\hline Ichneumonids & 2 & 3.9 & 1 & 0 & 9 & 6.3 & 4 & 69 & 1 & 1.0 & 0 & 0 & 3 & 2.0 & 0 & 0 \\
\hline Other & 12 & 6.9 & 8 & 21 & 7 & 1.0 & 0 & 0 & 6 & 5.2 & 2 & 26 & 6 & 5.6 & 2 & 38 \\
\hline
\end{tabular}

$V$ no. of individuals in video records (and sample size for $U$ ), $C$ no. of captured individuals (and sample size for PL), $P L$ average pollen loads (no. of pollen grains), $U$ mean no. of umbellets visited within an umbel (calculated based on video-recorded visits), $M$ male (staminate) phase umbels, $F$ female (pistillate) phase umbels

Fig. 4 Two most important groups of the Angelica sylvestris pollen exporters (on male phase umbels, M) and importers (on female phase umbels, F) in the years 2006-2007 according to their share in IC values. Black slice in each graph indicates summed percentage importance for the remaining groups (i.e., Non-hairy syrphids, Bees, Wasps, Ichneumonids, Beetles and Other)
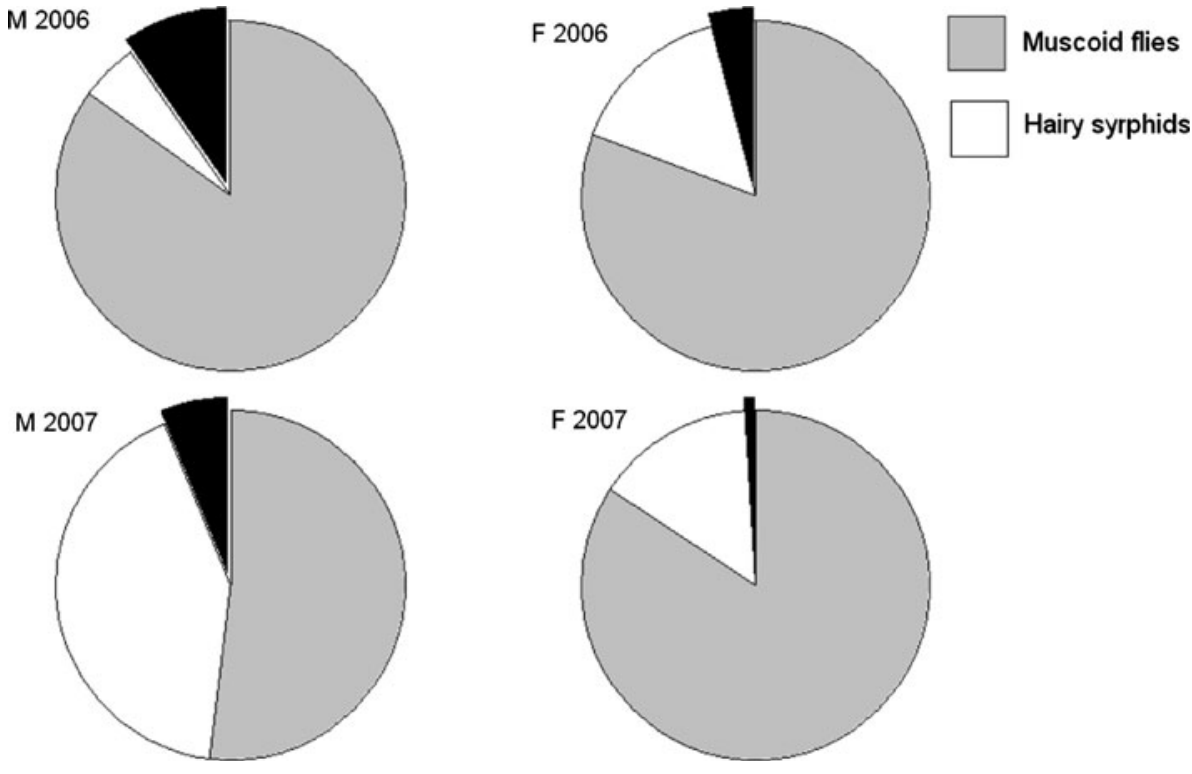

during pollen load analyses, approximately $30 \%$ of these taxa do not carry any pollen. The analysis of pollinator importance revealed that the plant is pollinated by a relatively constant assemblage of insects, mostly by Medium, Large muscid and Lucilia flies, which may differ in their performance from year to year and were assigned to various morphospecies, but in general exhibit a similar body plan and behavior, and we included them into a single functional group of Muscoid flies (Fig. 4).

Although flowers of $A$. sylvestris, similarly to many other Apiaceae, lack any visually specialized floral traits that would restrict some insects from visiting them, such specialized cues may also involve chemical signals, e.g., flower odors or nectar components, that attract or deter certain groups of pollinators. As demonstrated for this plant, there are considerable intraspecific differences in the composition of floral scents between populations of A. sylvestris (Tollsten et al. 1994). As suggested by the authors this can be an adaptive character leading to attraction of specific pollinators, but they can perhaps also function as a filter for other visitor groups. Such a type of phenotypic, instead of morphological, specialization was for instance found in Pachycarpus grandiflorus, an African milkweed (Apocynaceae), which although a typical example of generalist floral morphology, is exclusively visited and effectively pollinated by spider-hunting 
Table 3 Pollination importance of all the insect morphospecies recorded on umbels of Angelica sylvestris in the years 2006-2007

\begin{tabular}{|c|c|c|c|c|c|c|}
\hline & \multicolumn{3}{|l|}{2006} & \multicolumn{3}{|c|}{2007} \\
\hline & $I_{\mathrm{m}}$ & $I_{\mathrm{f}}$ & $I_{\mathrm{f}} / I_{\mathrm{m}}$ & $I_{\mathrm{m}}$ & $I_{\mathrm{f}}$ & $I_{\mathrm{f}} / I_{\mathrm{m}}$ \\
\hline Medium muscids & 9.8 & 9.6 & $0.98 *$ & 1.7 & 1.1 & $0.67 *$ \\
\hline Large muscids & 12.6 & 5.8 & $0.46^{*}$ & 4.6 & 2.6 & $0.58^{*}$ \\
\hline Hairy syrphids & 1.7 & 4.4 & $2.53 *$ & 6.5 & 2.4 & $0.37 *$ \\
\hline Non-hairy syrphids & 0.1 & 0.2 & 2.90 & 0.0 & 0.0 & 0.79 \\
\hline Lucilia & 4.7 & 7.6 & $1.61 *$ & 1.8 & 10.0 & $5.69^{*}$ \\
\hline Bees & 0.4 & 0.0 & 0.00 & 0.8 & $\mathrm{x}$ & \\
\hline Wasps & $\mathrm{x}$ & 0.4 & & 0.0 & $\mathrm{x}$ & \\
\hline Ichneumonids & 0.0 & 0.3 & & $\mathrm{x}$ & $\mathrm{x}$ & \\
\hline Beetles & 2.5 & 0.3 & 0.11 & $\mathrm{x}$ & $\mathrm{x}$ & \\
\hline Other & 0.1 & 0.0 & 0.00 & 0.1 & 0.1 & 1.29 \\
\hline
\end{tabular}

$x$ No data

Blank spaces indicate cases where $I_{\mathrm{f}} / I_{\mathrm{m}}$ could not be calculated

An asterisk denotes cases that in the particular study year jointly meet the following two criteria $\left(I_{\mathrm{f}} / I_{\mathrm{m}}\right)>0$ and $\mathrm{IC}_{\mathrm{f}}>1 \%$. For details on $I$ calculation, see Materials and methods

pompilid wasps (Shuttleworth and Johnson 2009). As demonstrated by these authors, olfactory cues were found to be primary attractants in the system; also the plant produced nectar that was unpalatable to honeybees. Nectar partitioning can function in this way too; for instance, in Apiaceae it is produced in tiny quantities by numerous flowers, which probably makes umbels unattractive for large pollinators with higher energy demands, filtering out some groups of potential pollinators such as bees (Ollerton et al. 2007).

If we define specialization of a pollination system as "successful pollination by a small number of animal species" (Armbruster et al. 1999), our results indicate that A. sylvestris should be regarded as ecologically generalized. On the other hand, if we assume that a functional rather than taxonomical approach is true, and specialization is implied when the pollination is accomplished via interaction with only a small subset of functionally grouped potential pollinators (Fenster et al. 2004), our study plant may be termed functionally specialized because it is abundantly visited and pollinated mostly by Muscoid flies and Hairy syrphids, and hardly visited by other insect groups, e.g., bumblebees or solitary bees, present in the studied community (M. Zych and J. Goldstein, personal observation). Although this group consists of over 22 species, we may assume that, from the plant's perspective, it consists of functionally equivalent pollinators (sensu Zamora 2000; Gómez and Zamora 2006, and literature cited) as all members of the Muscoid flies and Hairy syrphid groups exhibit a similar body plan and hairiness, and carry significant amounts of pollen (Table 2) far exceeding that necessary to pollinate a single flower. Relative equivalence in effectiveness of a large set of visitors' taxa and an economical way of pollination of a single flower (theoretically two viable grains suffice as there are only two ovules) suggest that in this case specialization on the most abundant pollinator is possible, which for A. sylvestris means a group of morphologically similar Muscoid flies. Even though the taxonomical composition of these morphospecies will probably vary in time and space, one may expect similar selective pressures exerted on populations even in various geographical conditions leading to relatively stable system with no additional 'improvements' (i.e., morphological fine-tuning to a particular insect taxon).

There are no available data on the importance of A. sylvestris pollinators throughout its geographic range, but the visitation data from several localities given by Knuth (1898) suggest the presence of the same insect functional groups in most of studied cases. If the above is true, then A. sylvestris, being a functional specialist, could be an example of "the adaptive generalization" (sensu Gómez and Zamora 2006) of its floral morphology.

Of course another explanation of relatively 'unspecialized' flower morphology in A. sylvestris (and possibly in many other Apiaceae) is a process of "nonadaptive generalization" (Gómez and Zamora 2006), which would occur when there is a shift in the most important pollinators (morphospecies) whose populations are subject to variation in time and space (i.e., muscid flies are replaced by beetles or solitary bees in subsequent years or adjacent populations), resulting in a geographic and temporal mosaic of specializations, with various levels of specialization/generalization at the population or regional level (Thompson 1994). Empirical data on these aspects of evolution of pollination systems show a high degree of variation of generalization levels for different populations and even individuals, suggesting that it is not necessarily an invariant species-level property (Herrera 2005). Paradoxically, in either of the above options, the evolutionary results for A. sylvestris would probably be the same-a relatively uniform and 'unspecialized' morphology of flowers-as in either case, a temporally and geographically stable set of pollinators versus greatly fluctuating groups of various pollinators exerting divergent selective pressures, easily accessible flowers are advantageous in terms of the reproductive success of local populations. As suggested for another umbellifer, H. sphondylium, this system also allows relatively unproblematic, in terms of sexual reproduction, colonization of new sites, even in the absence of "most effective" pollinators (Zych 2007). However, to test these hypotheses, a look at the geographical variation of the pollination system and specifically at insects' effectiveness is necessary, because as demonstrated for T. incisa subsp. incisa (Davila and Wardle 2007, 2008), it can show 
considerable variation both geographically and temporally. Also, as noted above, our results refer only to ecological specialization/generalization, since for evolutionary trends the broad phylogenetic background is necessary to compare the studied plant with its closest relatives: sister taxa or, ideally, ancestral group (Fenster et al. 2004).

It has been already pointed out in studies on Apiaceae that insect activities on flowers can vary among years, which greatly reduces the utility of single season studies (Lamborn and Ollerton 2000; Zych 2007; Davila and Wardle 2008, for references on other plant groups, see, e.g., Gómez and Zamora 2006). In our studies the effect of the year was also clearly significant (Table 1) in terms of a reduced number of visits in the much colder and rainy year 2007 as compared to the dry and sunny summer of 2006 (Fig. 2, mean temperature/rainfall in study region: $21^{\circ} \mathrm{C} /$ $30 \mathrm{~mm}$ in July 2006 versus $18^{\circ} \mathrm{C} / 100 \mathrm{~mm}$ in July 2007, IMGW 2009). Another factor that influenced the insect behavior was time of day, which highlights the importance of covering intra-seasonal variation in insect activity as well as their diurnal feeding behavior. Similarly to studies of H. sphondylium (Zych 2006) and T. incisa subsp. incisa (Davila and Wardle 2008), for most of insect visitors the peak activity on A. sylvestris umbels was recorded during midday, with significant differences recorded, however, only for Muscoid flies (Fig. 3).

Surprisingly, in the present work none of the insect visitor groups showed any preferences towards a particular umbel sexual phase (Table 1, Fig. 2), which was the case in studies on European H. sphondylium (Zych 2007), Australian T. incisa subsp. incisa (Davila and Wardle 2007) or North American Pseudocymopterus montanus (Schlessman et al. 2004). In all the cited cases the male phase umbels (composed of flowers in the staminate phase) were visited significantly more often than female phase inflorescences, and, as shown for H. sphondylium, some insects (over $30 \%$ of the represented taxa) visited exclusively, and actually parasitized on, male phase flowers since they utilized pollen and nectar but did not contribute to pollination (Zych 2007). Such discrimination seems possible in plants where pollinators can detect differences in floral resources or other phenotypic characters of either sexual phase. Perhaps in case of A. sylvestris it is difficult as petals, anthers and pollen grains of the plant are rather uniformly greenish-yellow in coloration when compared, for instance, to white petals and clearly yellow anthers of H. sphondylium subsp. sphondylium. Another explanation is that preferences towards pollenivory can be weaker in some dipterans that feed preferentially on nectar produced in either the umbel sexual phase in A. sylvestris (in some syrphid flies they can even be sex-dependent, with males preferentially feeding on nectar and females on pollen; M. Werner et al., personal communication).

\section{Conclusions}

Considering the above-presented results, it is difficult to give a single answer to the question of the specialization of the pollination system of $A$. sylvestris. Its rather "unspecialized" floral morphology, as perceived by earlier workers, would suggest little or no ecological specialization on particular insect species, which seems true when we look at the number of insect species. However, if we apply more broad functional definition of pollination agents (Fenster et al. 2004), it can be regarded as functionally specialized, similarly to Hedera helix described by Ollerton et al. (2007). These considerations imply another question about the conditions when the evolution of specialization is possible and whether specialization of pollination systems is always invariantly associated with morphological "fine tuning" or it can be achieved via other evolutionary pathways. The cases of A. sylvestris and some other Apiaceae plants (e.g., Zych 2007) suggest it can be true. There are some examples in the literature of morphologically advanced flowers visited by a relatively wide range of pollinators (e.g., Herrera 1996 and references within), and studies of some members of Apiaceae show that these plants can serve as an example of a reverse phenomenon. Perhaps studies of other phenotypic traits of umbelliferous plants, apart from the flower "bauplan," such as flower color, scent or nectar composition, will reveal such relationships, as was shown for the milkweed $P$. grandiflorus (Shuttleworth and Johnson 2009). However, in attempts to give some more general statements on pollination systems of umbellifers, caution must be taken because, although similar in appearance, they may differ in the phenotypic generalization/specialization level from species to species. This is in concordance with Ellis and Ellis-Adam's (1994) suggestions that close taxonomical, morphological and sometimes even ecological proximity is not necessarily a good predictor of the plants' pollination systems, which indicates the necessity of more studies being conducted before any coherent conclusions can be drawn.

Acknowledgments We thank P. Niemczyk for help in collecting field data and laboratory analyses, the landlords of the village Kleczkowo for permission to access their meadows, and A. DraberMońko, A. Krzysztofiak, and P. Tykarski for insect identification. R. R. Junker, M. Schlessman, M. Stpiczyńska, and two anonymous reviewers made useful and inspiring comments on earlier versions of the manuscript. The study was partly financed by the Departmental Grant BW 1720/69 (to M.Z.) from the Faculty of Biology, University of Warsaw.

Open Access This article is distributed under the terms of the Creative Commons Attribution Noncommercial License which permits any noncommercial use, distribution, and reproduction in any medium, provided the original author(s) and source are credited. 


\section{Appendix 1}

Table 4 Morphological and behavioral descriptions of the insect morphospecies observed on umbels of Angelica sylvestris L. (Apiaceae)

\begin{tabular}{|c|c|c|c|c|}
\hline Morphospecies & Description & Behaviour on umbels & Exemplary taxon & Functional group \\
\hline Medium muscids & $\begin{array}{l}\text { Hairy dipterans approx. 5-9 mm in } \\
\text { length, of the families Muscidae, } \\
\text { Calliphoridae, Sarcophagidae and } \\
\text { Tachinidae }\end{array}$ & $\begin{array}{l}\text { Fast movements between umbels, } \\
\text { long visits, many umbellets } \\
\text { touched }\end{array}$ & Musca autumnalis & Muscoid flies \\
\hline Large muscids & $\begin{array}{l}\text { Large hairy insects over } 10 \mathrm{~mm} \text { in } \\
\text { length, of the families Muscidae, } \\
\text { Calliphoridae, Sarcophagidae and } \\
\text { Tachinidae }\end{array}$ & $\begin{array}{l}\text { Fast movements between umbels, } \\
\text { long visits, many umbellets } \\
\text { touched }\end{array}$ & Calliphora vomitoria & Muscoid flies \\
\hline Lucilia & $\begin{array}{l}\text { Shiny green hairy calliphorid flies, } \\
5-10 \mathrm{~mm} \text { in length }\end{array}$ & $\begin{array}{l}\text { Fast movements between umbels, } \\
\text { long visits, many umbellets } \\
\text { touched }\end{array}$ & Lucilia caesar & Muscoid flies \\
\hline Hairy syrphids & $\begin{array}{l}\text { Large (usually over } 8 \mathrm{~mm} \text { in length) } \\
\text { and hairy flies of the family } \\
\text { Syrphidae }\end{array}$ & $\begin{array}{l}\text { Fast movements within and } \\
\text { between umbels, short visits }\end{array}$ & Eristalis anthophorina & Hairy syrphids \\
\hline Non-hairy syrphids & $\begin{array}{l}\text { Small and medium sized (below } 8 \mathrm{~mm} \\
\text { in length) flies of the family } \\
\text { Syrphidae, less hairy than the above }\end{array}$ & $\begin{array}{l}\text { "Shy" movements within and } \\
\text { between umbels, probing of } \\
\text { flowers, very few umbellets } \\
\text { touched }\end{array}$ & Syritta pipiens & Non-hairy syrphids \\
\hline Bees & $\begin{array}{l}\text { Honey bees, small worker } \\
\text { bumblebees, solitary bees }\end{array}$ & $\begin{array}{l}\text { Rather slow movements, very long } \\
\text { visits to male phase and very } \\
\text { short to female phase umbels }\end{array}$ & Apis mellifera & Bees \\
\hline Wasps & $\begin{array}{l}\text { Predatory hymenopterans of the } \\
\text { families Vespidae and Sphecidae }\end{array}$ & $\begin{array}{l}\text { Umbels touched usually during } \\
\text { patrolling flights }\end{array}$ & Paravespula rufa & Wasps \\
\hline Beetles & Insects of the order Coleoptera & $\begin{array}{l}\text { Slow movements, very long visits, } \\
\text { usually very few umbellets } \\
\text { touched }\end{array}$ & Rhagonycha fulva & Beetles \\
\hline Ichneumonids & $\begin{array}{l}\text { Parasitic hymenopterans of various } \\
\text { size }\end{array}$ & Very fast movements & Ichneumonidae & Ichneumonids \\
\hline Other & & & Miridae & Other \\
\hline
\end{tabular}

\section{References}

Armbruster WS, Di Stilio VS, Tuxill JD, Flors TC, Velasquez-Runk JL (1999) Covariance and decoupling of floral and vegetative traits in nine Neotropical plants: a re-evaluation of Berg's correlation-pleiadea concept. Am J Bot 86:39-55

Bell CR (1971) Breeding systems and floral biology of the Umbelliferae or evidence for specialization in unspecialized flowers. In: Heywood VH (ed) The biology and chemistry of the Umbelliferae. Academic Press, London, pp 93-107

Bell CR and Lindsey AH (1978) The umbel as a reproductive unit in the Apiaceae. In: Cauwet-Marc A-M, Carbonnier J (eds) Actes du 2eme Symposium International sur les Ombelliferes, Contributions pluridisciplinaires a la Systematique. Missouri Botanical Garden, pp. 739-747

Cannon JFM (1968) Angelica L. In: Tutin TG et al (eds) Flora Europaea, vol 2. Cambridge University Press, Cambridge, pp 357-358

Carvalheiro LG, Barbosa ERM, Memmott J (2008) Pollinator networks, alien species and the conservation of rare plants: Trinia glauca as a case study. J App Ecol 45:1419-1427

Corbet SA (2006) A typology of pollination systems: implications for crop management and the conservation of wild plants. In: Waser $\mathrm{NM}$, Ollerton $\mathrm{J}$ (eds) Plant-pollinator interactions from specialization to generalization. The University of Chicago Press, Chicago, pp 315-340

Cruden RW (1988) Temporal dioecism: systematic breadth, associated traits, and temporal patterns. Bot Gaz 149:1-15

Cruden RW, Hermann-Parker SM (1977) Temporal dioecism: an alternative to dioecism? Evolution 31:863-866

Davila YC, Wardle GM (2002) Reproductive ecology of the Australian herb Trachymene incisa subsp. incisa (Apiaceae). Aust J Bot 50:619-626

Davila YC, Wardle GM (2007) Bee boys and fly girls: do pollinators prefer male or female umbels in protandrous parsnip, Trachymene incisa (Apiaceae)? Aust Ecol 32:798-807

Davila YC, Wardle GM (2008) Variation in native pollinators in the absence of honeybees: implications for reproductive success of an Australian generalist-pollinated herb Trachymene incisa (Apiaceae). Bot J Linn Soc 156:479-490

Drabble E, Drabble H (1927) Some flowers and their dipteran visitors. New Phytol 26:115-123

Ellis WN, Ellis-Adam AC (1993) To make a meadow it takes a clover and a bee: the entomophilous flora of NW Europe and its insects. Contrib Zool 63:193-220

Ellis WN, Ellis-Adam AC (1994) Umbels are not alike. Entomol berich (Amsterdam) 54:191-199 
Faegri K, van der Pijl L (1966) The principles of pollination ecology. Pergamon Press, Oxford

Fenster CB, Ambruster WS, Wilson P, Dudash MR, Thomson JD (2004) Pollination syndromes and floral specialization. Ann Rev Ecol Evol Syst 35:375-403

Gómez JM, Zamora R (2006) Ecological factors that promote the evolution of generalization in pollination systems. In: Waser NM, Ollerton J (eds) Plant-pollinator interactions from specialization to generalization. The University of Chicago Press, Chicago, pp 145-166

Herrera CM (1996) Floral traits and plant adaptation to insect pollinators: a devil's advocate approach. In: Lloyd DG, Barrett SC (eds) Floral biology studies on floral evolution in animalpollinated plants. Chapman and Hall, New York, pp 65-87

Herrera CM (2005) Plant generalization on pollinators: species property or local phenomenon? Am J Bot 92:13-20

IMGW (Institute of Meteorology and Water Management) (2009) Monthly mean values of temperature and rainfall. http://www. imgw.pl/index.php?option=com_contentandview=articleandid= 354andItemid=298. Accessed 9 December 2009

Knuth P (1898) Handbuch der Blütenbiologie, II Band, 1. Teil: Ranunculaceae bis Compostitae. Verlag von Wilhelm Engelman

Lamborn E, Ollerton J (2000) Experimental assessment of the functional morphology of inflorescences of Daucus carota (Apiaceae): testing the 'fly catcher effect'. Funct Ecol 14:445-454

Lindsey AH (1984) Reproductive biology of Apiaceae. I. Floral visitors to Thaspium and Zizia and their importance in pollination. Am J Bot 71:375-387

Lindsey AH, Bell CR (1985) Reproductive biology of Apiaceae. II. Cryptic specialization and floral evolution in Thaspium and Zizia. Am J Bot 72:231-247

Molano-Flores B (2001) Reproductive biology of Eryngium yuccifolium (Apiaceae), a prairie species. J Torrey Bot Soc 128:1-6

Olesen JM, Dupont YL, Ehlers BK, Hansen DM (2007) The openess of a flower and its number of flower-visitor species. Taxon 56:729-738

Ollerton J, Killick A, Lamborn E, Watts S, Whiston M (2007) Multiple meanings and modes: on the many ways to be a generalist flower. Taxon 56:717-728

Pellmyr O (2002) Pollination by animals. In: Herrera CM, Pellmyr O (eds) Plant-animal interactions. An evolutionary approach. Blackwell, Oxford, pp 157-184

Pérez-Bañón C, Petanidou T, Marcos-García MÁ (2007) Pollination in small islands by occasional visitors: the case of Daucus carota subsp. commutatus (Apiaceae) in the Columbretes archipelago, Spain. Plant Ecol 192:133-151
Proctor M, Yeo P, Lack A (1996) Natural history of pollination. Harper Collins, London

Schlessman MA et al. (2004) Protogyny in Apiaceae, subfamily Apioideae: systematic and geographic distributions, associated traits, and evolutionary hypotheses. S Afr J Bot 70:475-487

Schlessman MA, Lloyd DG, Lowry PP II (1990) Evolution of sexual systems in New Caledonian Araliaceae. Mem NY Bot Gard 55:105-117

Schlessman MA, Underwood N, Watkins T, Graceffa LM, Cordray D (2004) Functions of staminate flowers in andromonoecious Pseudocymopterus montanus (Apiaceae, Apioideae). Plant Sp Biol 19:1-12

Shuttleworth A, Johnson SD (2009) The importance of scent and nectar filters in a sepcialized wasp-pollination system. Funct Ecol 23:931-940

Spalik K, Reduron J-P, Downie SR (2004) The phylogenetic position of Peucedanum sensu lato and allied genera and their placement in tribe Selineae (Apiaceae, subfamily Apioideae). Plant Syst Evol 243:189-210

StatSoft Inc. (2005) STATISTICA (data analysis software system), version 7.1. http://www.statsoft.com

Thompson JN (1994) The coevolutionary process. University of Chicago Press, Chicago

Tollsten L, Knudsen JT, Bergström LG (1994) Floral scent in generalistic Angelica (Apiaceae) — an adaptive character? Biochem Syst Ecol 22:161-169

Zamora R (2000) Functional equivalence in plant-animal interactions: ecological and evolutionary consequences. Oikos $88: 442-447$

Zych M (2002) Pollination biology of Heracleum sphondylium L. (Apiaceae). The advantages of being white and compact. Acta Soc Bot Pol 71:163-170

Zych M (2004) Pollination biology of Apiaceae—old myths and new perspectives. Wiad Bot (Bot News) 48:7-15

Zych M (2006) Diurnal activity of the key pollinators of Heracleum sphondylium L. (Apiaceae). Acta Agrobot 59:279-288

Zych M (2007) On flower visitors and true pollinators: the case of protandrous Heracleum sphondylium L. (Apiaceae). Plant Syst Evol 263:159-179

Zych M, Werblan-Jakubiec H (2004) A new, abundant locality of Polemonium caeruleum (Polemoniaceae) in the Mazovia region (NE Poland). Fragm Flor Geobot Pol 11:400-402

Zych M, Werblan-Jakubiec H (2005) A new locality of Betula humilis (Betulaceae) in NE Mazovia (NE Poland). Fragm Flor Geobot Pol 12:171-173

Zych M, Niemczyk P, Niemirski R (2007) Umbellifers as potential keystone species in restoration projects. Acta Agrobot 60:45-49 